\title{
Virtual Histology IVUS を用いた頸動脈プラークの評価
}

\author{
玉 川紀之酒井秀樹西村康 明
}

\section{Evaluating Carotid Artery Plaque using Virtual Histology IVUS}

by

\begin{abstract}
Noriyuki Tamakawa, M.D., Hideki Sakai, M.D., and Yasuaki Nishimura, M.D.
from
\end{abstract}

Department of Neurosurgery, National Hospital Organization Toyohashi Medical Center

Carotid artery stenting (CAS) has become a widely-used option to treat patients with carotid stenosis. Although technical improvements have led to a decrease in complications related to CAS, distal embolism continues to be a problem. To ensure the safety of CAS, the plaque characteristics must be clearly understood before commencing with the procedure. While ultrasonography (US) is a non-invasive, highly effective method for evaluating the plaque characteristics, interpretation of the results is subjective and the assessment of highpositioned plaques is difficult.

We analyzed the suitability and efficacy of Virtual Histology IVUS (VH-IVUS) for the assessment of carotid stenosis.

This method was used in 10 patients with CAS ; they underwent color-mapping for 4 types of plaque components, i.e. fibrous-, fibro-fatty-, and calcium components, and necrotic core. The results of VH-IVUS analysis showed that soft- and calcified plaques tended to contain a grater amount of debris.We suggest that the evaluation of plaques by VH-IVUS yields highly reproducible and objective results that can be used to determine the necessity of protective devices, and as an aid in the selection of stents and the setting of the inflation pressure at time of PTA in patients undergoing CAS.

(Received August 7, 2006 ; accepted November 27, 2006)

Key words : Virtual Histology IVUS, carotid artery stenting, atheromatous plaque, ICA stenosis Jpn J Neurosurg (Tokyo) $16: 569-575,2007$

\section{はじめに}

近年, 頸部頸動脈狭窄症例に対し，頸動脈ステント留 置術（carotid artery stenting； CAS）が治療の選択肢の 一つとして普及しつつある. 最近の deviceの発達に伴 い, CASの合併症は減少しつつあるが, distal embolism による合併症は依然大きな問題として残されている。こ のためCAS の手技をより安全に行っていくには, 頸動 脈プラークの性状を術前に正確に把握し, 治療法や de- vice を選択することが重要である。プラークの性状評価 をする検査法の中でも, 経体表エコー検査（ultrasonography；US）は非侵襲的で大変有用性の高い検査 法であり，その診断精度は年々向上しつつある。しかし ながら従来のUSでは，その性状判定は検查施行者の主 観的診断が主体となり，また日本人に多い高位プラーク では，十分なプラークの診断ができないこともある。そ こで今回われわ机は, 冠動脈プラークの性状評価用に開 発された Virtual Histology IVUS ${ }^{\mathrm{TM}}$ (VH-IVUS) を頸動脈

独立行政法人国立病院機構豊橋医療センター脳神経外科 $/ \bar{T} 440-8510$ 豊橋市飯村町字浜道上 50 〔連絡先：玉川紀之〕

Address reprint requests to : Noriyuki Tamakawa, M.D., Department of Neurosurgery, National Hospital Organization, Toyohashi Medical Center, 50 Hamamichikami, Imure-cho, Toyohashi-shi, Aichi 440-8510, Japan 
Table 1 Summary of the patients with US, 3D-CT, black blood MRI and VH-IVUS findings

\begin{tabular}{|c|c|c|c|c|c|c|c|c|}
\hline Case & Age & Sex & Symptom & Ultrasonography & $3 \mathrm{D}-\mathrm{CT}$ & Black blood MRI & VH-IVUS & Debris \\
\hline 1 & 74 & male & asymptomatic & $\begin{array}{c}\text { low echoic } \\
\text { (homogenous) }\end{array}$ & n.e. & soft plaque(hemorrhage) & mixed & $(++)$ \\
\hline 2 & 75 & male & asymptomatic & n.e. & n.e. & soft plaque (hemorrhage) & mixed & $(+)$ \\
\hline 3 & 67 & female & asymptomatic & $\begin{array}{c}\text { high echoic } \\
\text { (acoustic shadow) }\end{array}$ & $\begin{array}{c}\text { calc } \\
(+++)\end{array}$ & n.e. & $\begin{array}{l}\text { calcified } \\
\text { rich }\end{array}$ & $(+++)$ \\
\hline 4 & 68 & male & symptomatic & n.e. & n.e. & soft plaque (hemorrhage) & lipid rich & $(+)$ \\
\hline 5 & 75 & male & symptomatic & $\begin{array}{l}\text { high \& low echoic } \\
\text { (heterogeneous) }\end{array}$ & $\operatorname{calc}(+)$ & $\begin{array}{c}\text { soft plaque } \\
\text { (lipid }+ \text { hemorrhage })\end{array}$ & $\begin{array}{l}\text { fibrous } \\
\text { rich }\end{array}$ & $( \pm)$ \\
\hline 6 & 63 & female & asymptomatic & high echoic & $\operatorname{calc}(+)$ & hard plaque (fibrous plaque) & mixed & $( \pm)$ \\
\hline 7 & 73 & male & asymptomatic & $\begin{array}{c}\text { low echoic } \\
\text { (homogenous) }\end{array}$ & $\operatorname{calc}(-)$ & hard plaque (fibrous plaque) & $\begin{array}{l}\text { fibrous } \\
\text { rich }\end{array}$ & $( \pm)$ \\
\hline 8 & 71 & male & symptomatic & $\begin{array}{l}\text { high \& low echoic } \\
\text { (heterogeneous) }\end{array}$ & $\operatorname{calc}(++)$ & soft plaque (lipid deposits) & mixed & $(++)$ \\
\hline 9 & 59 & male & asymptomatic & $\begin{array}{c}\text { low echoic } \\
\text { (homogenous) }\end{array}$ & $\operatorname{calc}(+)$ & soft plaque (lipid deposits) & lipid rich & $(++)$ \\
\hline 10 & 79 & male & symptomatic & $\begin{array}{c}\text { high echoic } \\
\text { (homogenous) }\end{array}$ & $\operatorname{calc}(++)$ & hard plaque (fibrous plaque) & mixed & $(+)$ \\
\hline
\end{tabular}

n.e. ; not examined, calc ; calcification

Table 2 Total plaque analysis by VH-IVUS

\begin{tabular}{|c|c|c|c|c|c|c|c|c|}
\hline Case & $\begin{array}{c}\text { Plaque } \\
\text { volume } \\
\left(\mathrm{mm}^{3}\right)\end{array}$ & $\begin{array}{c}\text { Segment } \\
\text { length } \\
(\mathrm{mm})\end{array}$ & $\begin{array}{c}\text { Fibrous }(\%) \\
\text { (green) }\end{array}$ & $\begin{array}{c}\text { Fibro-fatty }(\%) \\
\text { (light green) }\end{array}$ & $\begin{array}{c}\text { Calcium }(\%) \\
\text { (white) }\end{array}$ & $\begin{array}{c}\text { Lipid core }(\%) \\
\text { (red) }\end{array}$ & VH-IVUS & Debris \\
\hline 1 & 234.8 & 9.3 & 62 & 35 & 1 & 2 & mixed & $(++)$ \\
\hline 2 & 240.4 & 15.6 & 76 & 22 & 1 & 1 & mixed & $(+)$ \\
\hline 3 & 564.7 & 28.9 & 51 & 25 & 6 & 7 & calcified rich & $(+++)$ \\
\hline 4 & 252.5 & 15.2 & 64 & 33 & 1 & 3 & lipid rich & $(+)$ \\
\hline 5 & 286.8 & 17.7 & 77 & 19 & 2 & 2 & fibrous rich & $( \pm)$ \\
\hline 6 & 403.0 & 18.5 & 64 & 23 & 2 & 10 & mixed & $( \pm)$ \\
\hline 7 & 260.2 & 11.3 & 60 & 30 & 2 & 9 & fibrous rich & $( \pm)$ \\
\hline 8 & 705.8 & 39.8 & 53 & 20 & 5 & 22 & mixed & $(++)$ \\
\hline 9 & 153.1 & 9.2 & 55 & 42 & 2 & 2 & lipid rich & $(++)$ \\
\hline 10 & 603.4 & 20.8 & 70 & 21 & 4 & 5 & mixed & $(+)$ \\
\hline
\end{tabular}

プラークの評価に応用し, 病変の十分な評価が可能かど うか, US，3D-CT, MRI などの他検査と比較検討して 報告する。

\section{対象および方法}

2005 年 8 月〜 2006 年 4 月の間に CAS を行った 10 例, 10 病変を対象とした。男性 8 例，女性 2 例，年齢は 59 〜 79 歳であった (平均年齢 70.3 歳).

使用機種は, IVUSカテーテル：Volcano 社製 Eagle Eye Gold/IVUS 装置: Volcano 社製 IVG3オラクルイ メージングシステムを使用した．VH-IVUS では，IVUS から得られる生のエコー信号（RF 信号）を区間ごとに 時系列信号を区切り，その区間からのスペクトルをまず 得て，そのスペクトルから約 8 種類のさまざまなパラ
メー夕（最大出力, 最大出力時の周波数, 最小出力, 最 小出力時の周波数，線形回帰線の傾き，y切片，ミッド バンドの出力, integrated backscatter）を組み合わせて デジタル化を行う。これをあらかじめ経験的に作り上げ た分類木 (classification tree) に従って組織をピクセル ごとに解析し，プラークを線維化 (緑)，線維脂質化（黄 緑), 壊死 (赤), 石灰化（白）にカラーマッピングでき るといわれている。

今回の検討では，全例 CAS の施行当日のステント留 置直前にVH-IVUS を行い，プラーク性状を評価した。 そしてVH-IVUS 所見によりそれぞれのプラーク性状 を, (1) fibrous rich, (2) lipid rich, (3) calcified rich, (4) mixedの 4 つのパターンに分類した。全例において Percusurge GuardWire plus (Medtronics) により distal protectionを行い，後拡張の後 Thrombuster II により de- 

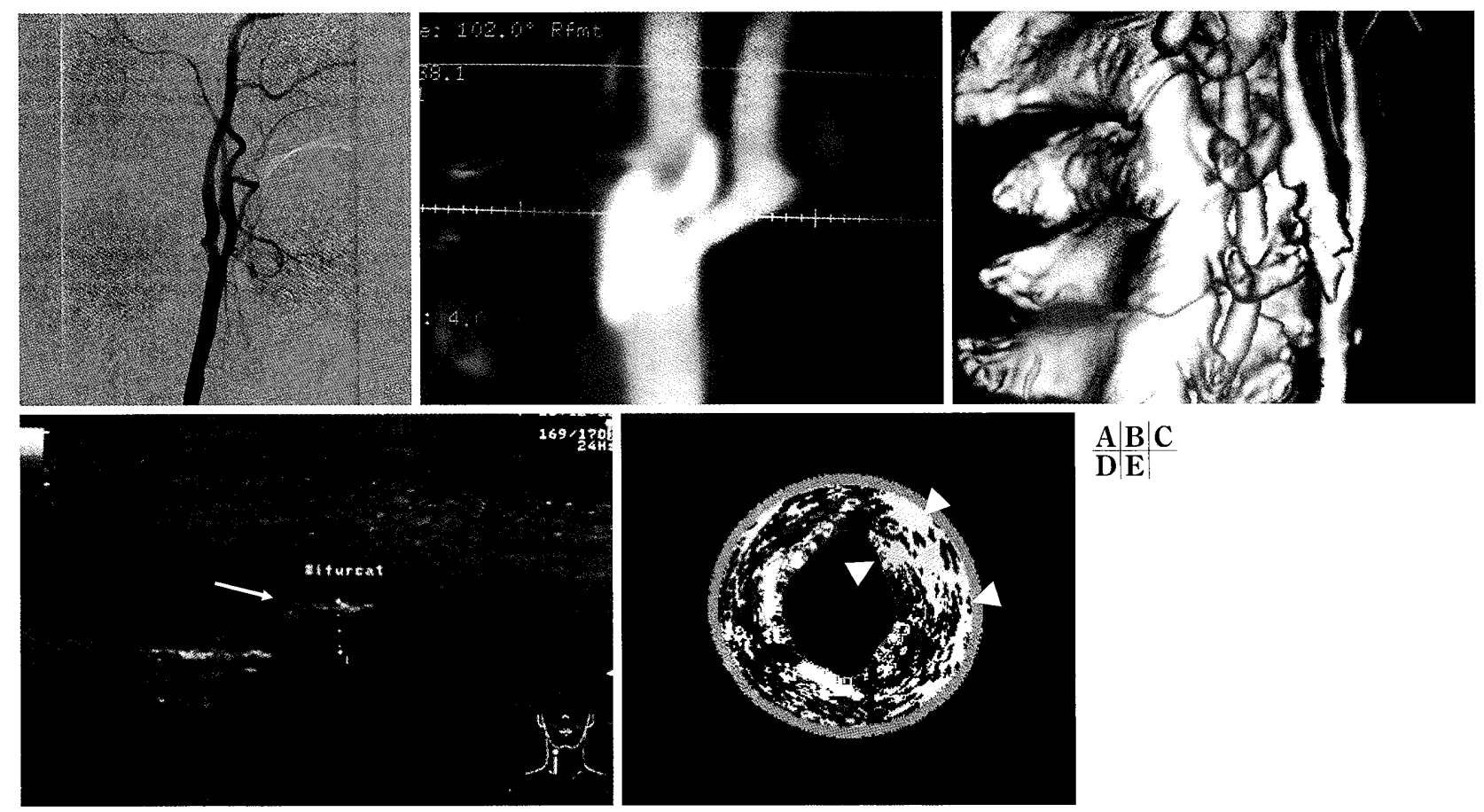

$\underline{A}|\mathbf{B}| \mathbf{C}$

$\overline{\mathbf{D}|\mathbf{E}|}$

Fig. 1 Case 3

A : Right carotid angiogram revealed $80 \%$ stenosis of the right proximal internal carotid artery.

B, C : Three-dimensional computed tomography (3D-CT) analysis of the carotid plaque. Severe calcification was evident in the plaque. Components other than calcification were difficult to evaluate, and the location of calcification within the plaque could not be determined.

D : Ultrasonography (US) showed severe calcification. The presence of shadowing (arrow) prevented adequate assessment of the plaque.

E : VH-IVUS of the plaque. Note the $270^{\circ}$ arc of calcification on the plaque surface. A fibro-fatty component was present at a site opposite the area of calcification (arrowheads).

bris 混入の血液を回収し, 細胞分離用のフィルター (Falcon, Cell Strainer 2340）にてろ過した. フィルター に残存した debrisを観察し, debris 量を多量, 中等量, 少量に分類した。またCASの施行前に, US, 3D-CT, MRI（black blood 法）を併せて行い頸動脈プラークの評 価をし，VH-IVUSとの比較検討を試みた。

\section{結 果}

これらの症例のプラークをVH-IVUSにより分類する と, (1) fibrous rich 2 例, (2) lipid rich 2 例, (3) calcified rich 1 例, (4) mixed 5 例であった（Table 1). CAS の際 に得られた debris 量は, fibrous rich は 2 例とも少量, lipid rich は 1 例が少量もう1例が中等量, calcified rich の 1 例は多量, mixed はそれぞれ中等量 2 例, 少量 3 例 であった。一方, US, 3D-CT, MRI との比較では, 石 灰化病変においてVH-IVUS は 3D-CT との相関がよく 夕られるが, black blood MRIでは石灰化の診断は困難 であった。一方, 線維脂質化病変においては, case 5 の
1 例を除いて black blood MRI との相関がよくみられた. US とは，だいたいVH-IVUS との相関がみられたが, 石灰化による描出不良, 解像度の問題などにより十分な 情報がそしく，比較が正確に行えなかった．またVHIVUS によるプラーク全体の解析において，それぞれの 組織の比率と debris 量との検討を行った結果, プラー ク全体に括いて fibrous lesion が 60\% 以下の場合 debris が多量になる傾向が認められた（Table 2).これらにつ き得られた debris が多量であった calcified rich (case 3), mixed (case 8), lipid rich（case 9) の 3 症例を提示する

(Fig. 1 3) .

\section{症例提示}

\section{【Case $3:$ calcified plaque】}

患 者 : 65 歳, 女性

狭心症に対する CABG (coronary artery bypass grafting）前のスクリーニング MRA にて右内頸動脈狭窄と診 断された. 脳血管撮影 (Fig. 1 A)，3D-CT (Fig. 1B, C), 

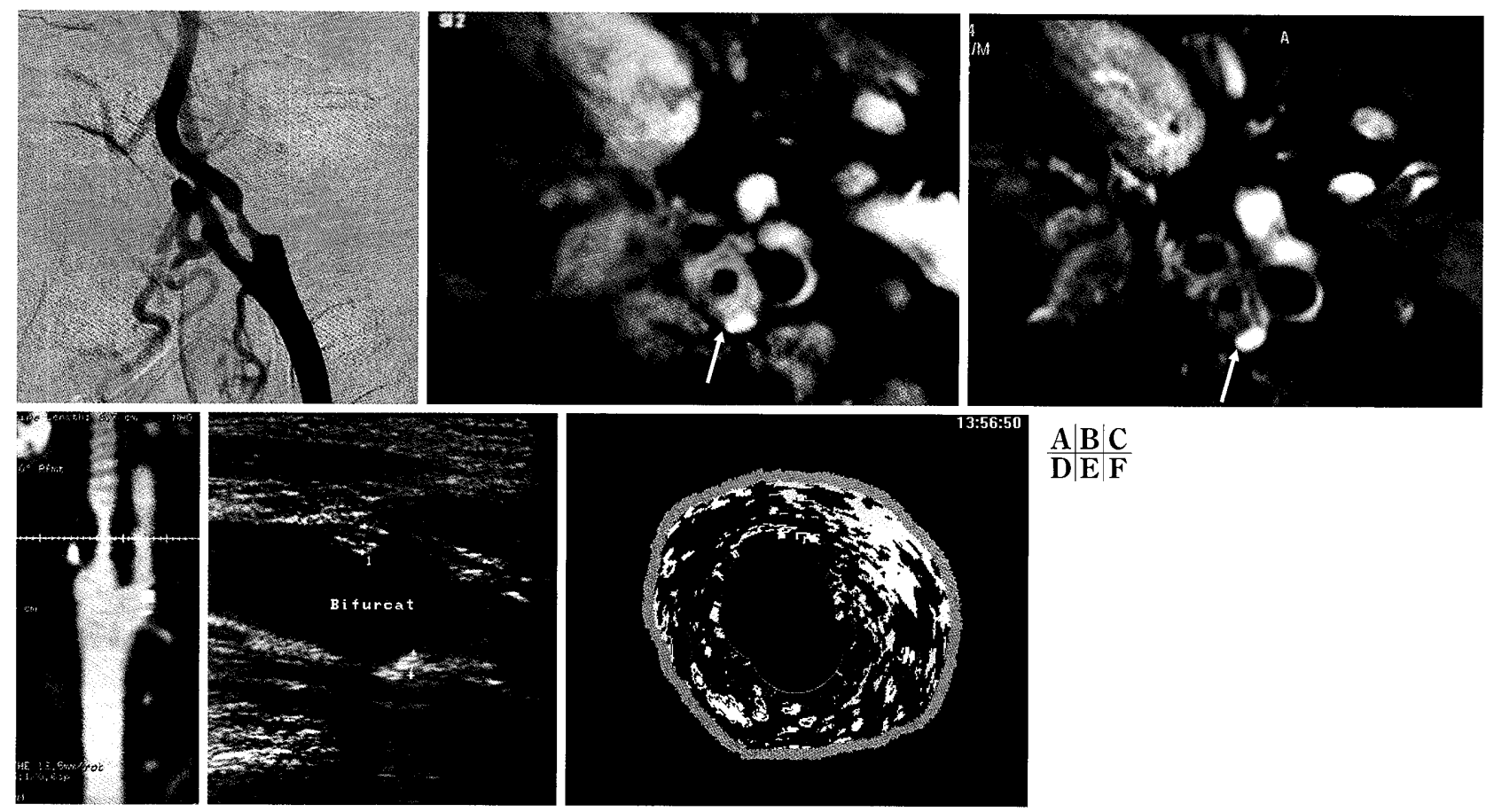

A $|\mathbf{B}| \mathbf{C}$

$\bar{D}|\mathbf{E}| \mathbf{F}$

Fig. 2 Case 8

A : Left carotid angiogram showed $80 \%$ stenosis of the left proximal internal carotid artery.

B, C : Black blood MRI of the plaque. T1 black blood (B) and T2 black blood (C) was visualized as high intensity area in the plaque (arrows). Diagnosis by black blood MRI was a soft plaque. The plaque intensity was heterogeneous. The arrow indicates a plaque on the left proximal internal carotid artery.

D : 3D-CT showed slight calcification in the plaque.

E : US of the left carotid artery. A heterogeneous high and low echoic plaque could be seen.

F : VH-IVUS of the plaque. A lipid core lesion was evident in the plaque.

US（Fig. 1D）では強い石灰化をプラーク内に認めた. プラークの VH-IVUS 所見はプラークの表面に強い石灰 化を認め（Fig. 1E） calcified rich と分類したが，プラー クは石灰化のみではなく石灰化病変の対側, 直下に fibro-fatty lesion が認められた. 3D-CT では同様に強い石 灰化を認めたが，石灰化の部位はプラークの表面である のか, 内部に存在するのか部位喨断は不可能であった。 USでは石灰化による shadowingにより評価不可能で あった。

\section{【Case $8:$ mixed plaque】}

\section{患 者: 71 歳, 男性}

感覚性失語にて発症し, MRIで左側頭葉に脳梗塞を 認めた. MRA で右内頸動脈狭窄が疑われ, 脳血管撮影 で右頸部頸動脈に $90 \%$ 狭窄を認めた（Fig. 2A）。プラー クの VH-IVUS 所見は lipid core lesion が狭窄部を中心に 非常に多く, lipid core と fibrous lesion の mixed と分類 した (Fig. 2E). black blood MRIでは soft プラークであ り (Fig. 2B, C)，3D-CT では石灰化が局所的に認められ
た（Fig. 2D）。術中に得られた debris 量は多量であった。

\section{【Case 9 : lipid rich plaque】}

\section{患 者: 59 歳, 男性}

狭心症に対する CABG 前のスクリーニング MRA にて 右内頸動脈狭窄と診断された。 3D-CTでは石灰化が軽 度に認められ（Fig. 3A）, black blood MRIでは soft プラー クの所見であった（Fig. 3B, C). プラークの VH-IVUS 所 見は全体に fibro-fatty の病変が強く lipid rich と分類した (Fig. 3D).

\section{考 察}

頸部頸動脈狭窄症の治療は,これまで頸部内頸動脈剝 離術（carotid endoarterectomy；CEA）が第一選択と なっていたが, 最近ではCASによる治療例が増加しつ つあり，またCEA と遜色ない臨床成績を挙げるように なってきている ${ }^{11)}$. 経皮経管血管形成術 (percutaneous transluminal angioplasty；PTA）による血管拡張は, バ 


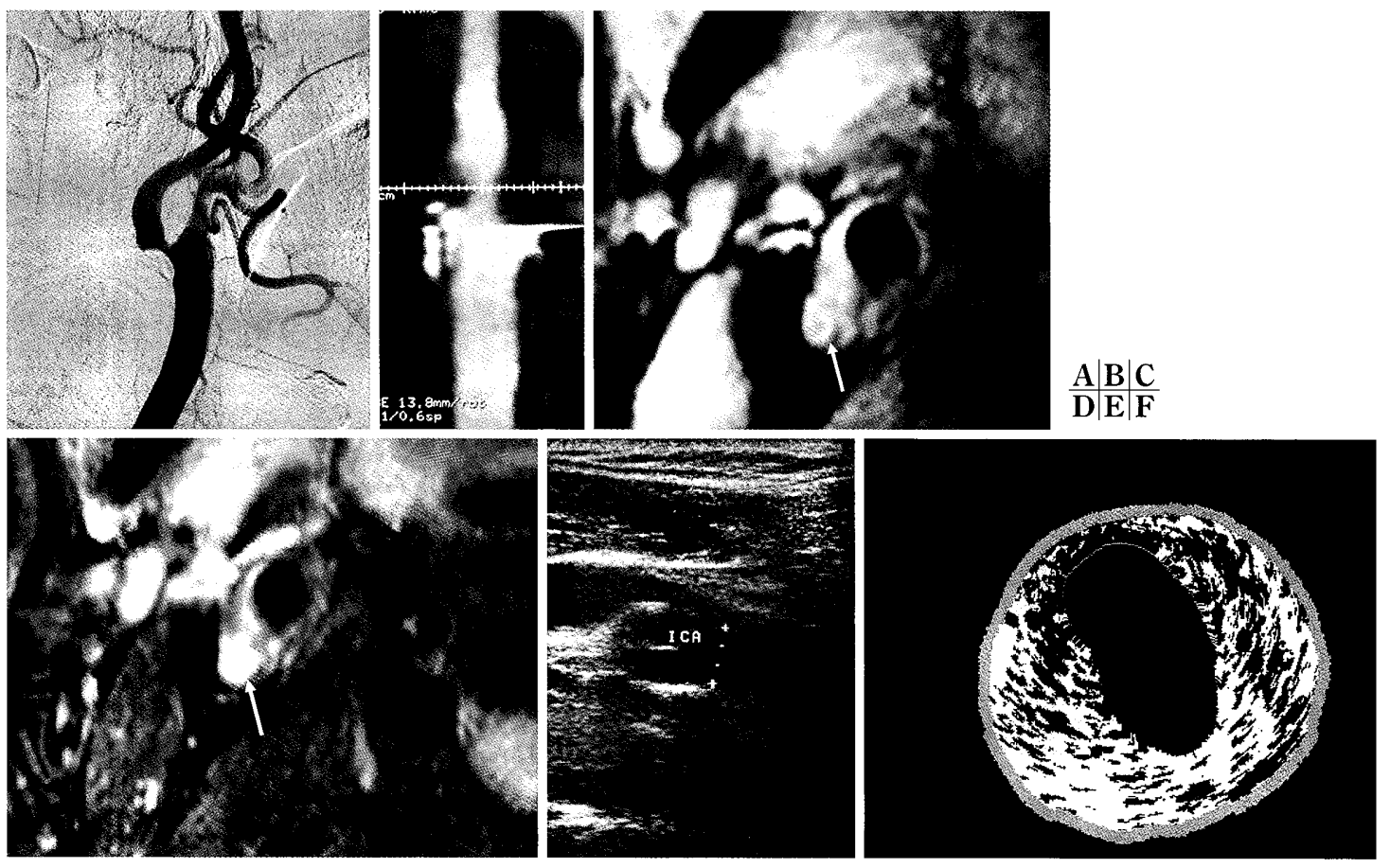

Fig. 3 Case 9

A : Right carotid angiogram showed $75 \%$ stenosis of the right proximal internal carotid artery.

B : 3D-CT showed slight calcification in the plaque.

C, D : Black blood MRI of the plaque. T1 black blood (B) showed iso- and T2 black blood (C) showed high intensity area in the plaque (arrow). Diagnosis by black blood MRI was a soft plaque. The arrow indicates a plaque on the right proximal internal carotid artery.

E : US of the right carotid artery. A homogeneous low echoic plaque could be seen.

F : VH-IVUS of the plaque. A fibro-fatty lesion was evident.

ルーンの拡張によって引き起こされる内膜の亀裂や中膜 の過伸展により得られるが3〉, この際にプラーク内の脂 肪や血栓が流出して ${ }^{5)}$, embolism が発生し脳塞栓の合併 症が起こることがCASの最大の合併症である ${ }^{4 / 6) 7)}$ 。こ のため distal embolismを防ぐ方法として各種の protection device が開発され利用されているが，完全にこれを 防御できるシステムはいまだ確立されていない. 現時点 でCASの手技の安全性を向上させるためにはプラーク 性状の術前診断が重要であり, その結果を踏まえ CEA の選択や protectionの方法の検討が必要である.プラー クの性状評価には超音波検査が有用であるが, その際の 観察のポイントとして，プラーク表面と内部の性状の評 価が必要である，表面性状としては，プラーク表面の不 整性や潰瘍の有無を評俩する。一方, プラーク内部の組 織性状はエコー信号の輝度分布により, 均質 (homoge-

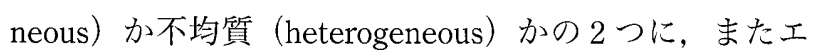
コー輝度から分けられ, 低輝度 (low or hypo-), 等輝度 (iso-), 高輝度 (hyper-) プラークの3つに分類される
ことが多い.しかし従来のエコー診断では検者の主観的 な判断が主体であり, 常に再現性の高い評価ができると は限らない。 またエコー輝度の定量化が難しく, 症例間 の比較も困難である.しかし，エコーでのプラーク性状 は CEA とCASの選択や protection 法の検討の際に非常 に重要な情報である. 特に不均質で低輝度プラークは不 安定プラークであり, CASの手技中に micro embolism が発生しやすく注意を要するといわれている。このた め, エコー画像の定量化で客観的評価が試みられるよう になり, 最近では冠動脈治療においてはVH-IVUS や Integrated Backscatter IVUS（IB-IVUS）などが開発され, プラーク性状のカラーマッピングが可能になってきた ${ }^{8)}$.

そこで, 今回われわれはVH-IVUS を頸動脈に応用 し，プラークのカラーマッピングを試みた。 その結果, プラークの表面および内部性状が視覚的に把握可能であ り, エコー検査に精通していなくても客観的評価が可能 であった.プラーク内部の組織性状は全例で不均質で あったが, 得られたデータによる組織の定量的分類で, 
われわれは, (1) fibrous rich, (2) lipid rich, (3) calcified rich, (4) mixedの 4 つのパターンにプラークを分類でき た。また，それらの治療の際の吸引できた debris 量を 比較した結果, fibrous lesion がプラーク全体の $60 \%$ 以 下の場合, debris が多量になる傾向があった（Table 2). これにより debris 量は，従来いわれているように lipid richの病変が多い傾向であることが再確認できた．

しかし術前に比較的 debris が少ないであろうと予測 した calcified rich, mixed プラークにも予想以上に多量 の debris が得られた。この所見を基にVH-IVUS のデー 夕を吟味すると, calcified richであってもプラークは不 均質であり, 石灰化の周围や対側壁には予想以上に fibro-fatty な柔らかい病変が存在していることが確認でき た. 石灰化の強いプラークでは, PTAの際十分な拡張 を得ようとして拡張圧を強くする傾向にあり，高い圧が 石灰化のみならず fibro-fatty な病変にかかり, 結果とし てこの部位の脂肪や血栓が多量に流出するのではないか と考えられた。一方プラーク性状を評価する他の画像診 断法としては, US, CT (3D-CT), MRI（black blood 法）などが行われている(1)29910)。頸部体表エコーは安 価，簡便で一般で普及しているが，屈曲蛇行の強い例や 石死化の強い例ではプラークの十分な情報を得ることが できないことや，前述のように検者の技量により評価が 異なったり，検者の主観的な評価になりやすいなどの欠 点がある. 3D-CTの空間分解能は高く, 石灰化部は容 易に評価できるが，(1)コントラストに劣る，(2)石灰化以 外のプラーク内の評価が困難, (3)石灰化でもプラーク内 での正確な部位の評価は不可能などの問題点が存在す る. black blood MRI は，高コントラストにプラークを 描出できるが，(1)血管拍動に伴うアーチファクトを伴っ たり, 線維性被膜が評価できない, (2)石灰化病変の描出 が困難などの欠点が存在する。これらに対し VH-IVUS での評価では，侵襲的であり繰り返し行うには不向きで あるが，プラーク内の十分な情報（石灰化, 線維性脂質 の正確な部位診断など）をカラーマッピングで得ること ができ，再現性や客観性に優れるなどの利点があり，非 常に有用性は高かった，今回，われわれの検討ではVHIVUS を全例ステント留置術直前に行っており, 治療法 の選択に直接つながってはいない.しかしこの VHIVUS のデータは，この後行われる CAS 手技中のバルー ンやステントの選択，PTA 拡張圧の設定には非常に有 用であった。また，フォローアップでの VH-IVUSの データは, 治療後の病変部の変化や再狭窄のメカニズム の解析に応用できる可能性があると考えられた。ささらに 今後 VHの technology が経体表エコーにも導入されれ
ば，その利用価値は大変高くなると予想され今後の開発 が期待される。

\section{結＼cjkstart語}

1）VH-IVUS は頸動脈プラークの性状を客観的に再現 性よく評価できた。

2) VH-IVUSのプラーク性状で, soft plaque もしくは calcified plaque と評価された症例では，CAS 時の debris 量が多い傾向にあった.

3）今後 VH-IVUS によるプラーク性状の評価は，CAS の protective deviceの選択などに応用できる可能性が示 唆された。

\section{文 献}

1) Alvarez-Linera J, Benito-Leon J, Escribano J, Campollo J, Gesto R : Prospective evaluation of carotid artery stenosis : Elliptic centric contrast-enhanced MR angiography and spiral CT angiography compared with digital subtraction angiography. AJNR Am J Neuroradiol 24: 1012-1019, 2003.

2) Borisch I, Horn M, Butz B, Zorger N, Draganski B, Hoelscher T, Bogdahn U, Link J : Preoperative evaluation of carotid artery stenosis : Comparison of contrast-enhanced MR angiography and duplex sonography with digital subtraction angiography. AJNR Am J Neuroradiol 24:1117$1122,2003$.

3) Castaneda-Zuniga WR, Formanek A, Tadavarthy M, Vlodaver Z, Edwards JE, Zollikofer C, Amplatz K : The mechanism of balloon angioplasty. Radiology $135: 565-571$, 1980.

4) Cohen JE, Lylyk P, Ferrario A, Gomori JM, Umansky F : Carotid stent angioplasty : The role of cerebral protection devices. Neurol Res 25:162-168, 2003.

5) Crawley F, Clifton A, Buckenham T, Loosemore T, Taylor RS, Brown MM : Comparison of hemodynamic cerebral ischemia and microembolic signals detected during carotid endarterectomy and carotid angioplasty. Stroke $\quad 28: 2460-$ 2464, 1997.

6) Kastrup A, Gröschel K, Krapf H, Brehm BR, Dichgans J, Schulz JB : Early outcome of carotid angioplasty and stenting with and without cerebral protection devices : A systematic review of the literature. Stroke $34: 813-819$, 2003.

7) Muller-Hulsbeck S, Jahnke T, Liess C, Glass C, Grimm J, Heller M : Comparison of various cerebral protection devices used for carotid artery stent placement : An in vitro experiment.J Vasc Interv Radiol $14: 613-620,2003$.

8) Nair A, Kuban BD, Tuzcu EM, Schoenhagen P, Nissen SE, Vince DG : Coronary plaque classification with intravascular ultrasound radiofrequency data analysis. Circulation $106: 2200-2206,2002$.

9) Nederkoorn PJ, van der Graaf Y, Hunink MG : Duplex ultrasound and magnetic resonance angiography compared with digital subtraction angiography in carotid artery stenosis : A systematic review. Stroke $34:$ 1324-1332, 2003.

10) Wardlaw JM, Chappell FM, Best JJ, Wartolowska K, Berry E ; NHS Research and Development Health Technology 
Assessment Carotid Stenosis Imaging Group : Non-invasive imaging compared with intra-arterial angiography in the diagnosis of symptomatic carotid stenosis : A metaanalysis. Lancet 367 (9521): 1503-1512, 2006.

11) Yadav JS, Wholey MH, Kuntz RE, Fayad P, Katzen BT,
Mishkel GJ, Bajwa TK, Whitlow P, Strickman NE, Jaff MR, Popma JJ, Snead DB, Cutlip DE, Firth BG, Ouriel K : Protected carotid-artery stenting versus endarterectomy in high-risk patients. N Engl J Med 351 : 1493-1501, 2004.

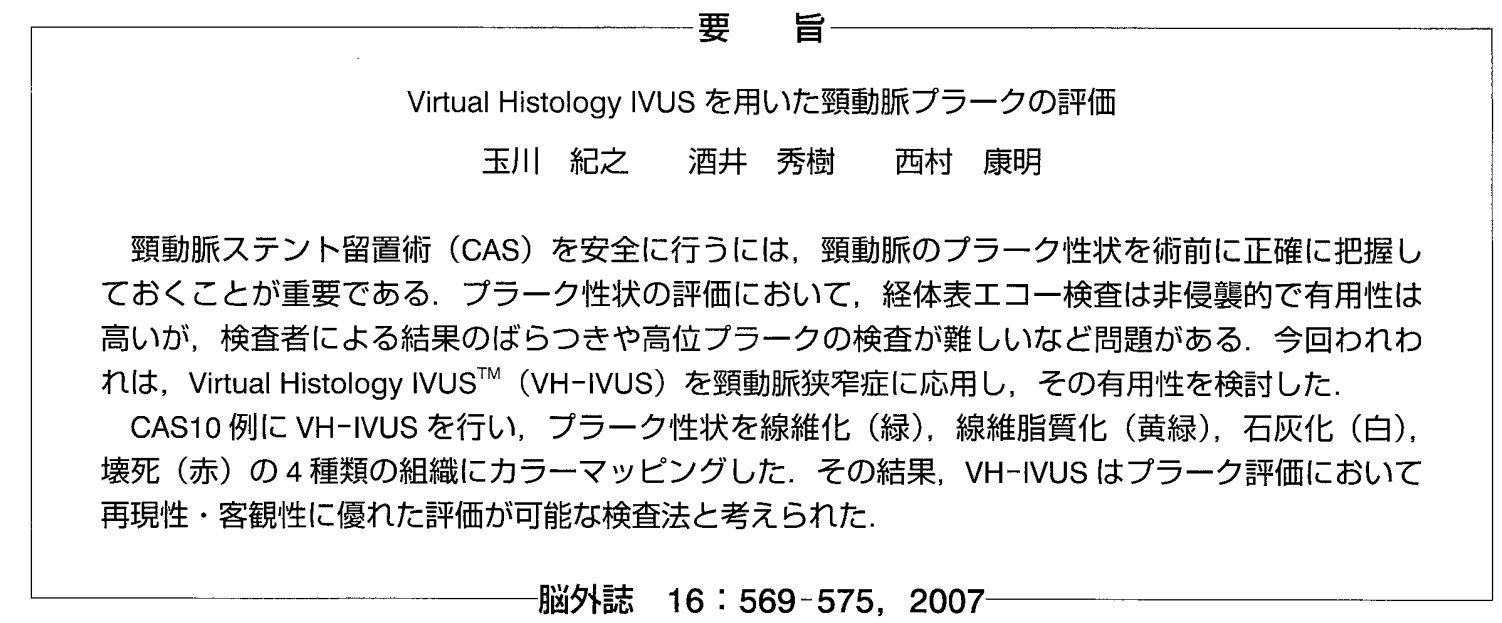

